\title{
Research on Supply Chain Optimization Strategy of Clothing Retail Industry under the Background of Big Data
}

\author{
Jingjing Liu \\ Business School, Wuhan Polytechnic, Guanshan Road, 463\#, Wuhan, China \\ 31909078@qq.com
}

Keywords: Big data; Clothing; Retail; Supply chain optimization; Strategy

\begin{abstract}
Supply Chain Management plays an important role in business management. Big data technology provides a new solution for the operation and optimization of supply chain. By analyzing the shortcomings of the supply chain operation in the traditional clothing industry, combined with the practical application of big data technology in the retail industry, this paper proposes various strategies for optimizing the supply chain of the clothing retail industry under the background of the big data era, such as realizing product traceability and accurate marketing, improve supply chain response speed and collaboration capabilities, achieve intelligent sub-storage, improve end-of-delivery efficiency, etc., in order to provide reference for the apparel retail industry to improve competitiveness.
\end{abstract}

\section{Introduction}

With the rapid development of information technology and Internet technology, a large amount of data has been generated in all fields around the world. According to international data company IDC's statistics, it is estimated that by 2020 , the global data volume will reach $35 \mathrm{ZB}(1 \mathrm{ZB}=1$ trillion GB). Opportunities for big data development and application have emerged, and the era of big data has arrived. The development, analysis and application of big data are infiltrating into all fields. The analysis, mining and use of big data has become one of the key factors for the success of modern enterprises, including the clothing retail industry.

\section{The Role of Information in the Operation of Enterprise Supply Chain}

The "Supply Chain" is built around the core enterprise, through the control of information flow, logistics and capital flow, it starts from the procurement of raw materials, and makes intermediate products and final products. Finally, the sales network sends the products to consumers. It is a functional network chain model that connects suppliers, manufacturers, distributors, retailers, and end users.

Information plays an important role in supply chain management. Information distortion can lead to a decline in supply chain efficiency and a bullwhip effect, and accurate, timely and shared information can benefit the entire supply chain. Information is the main aspect of modern competition.

The idea of supply chain management emphasizes the overall view of the supply chain, and gives the overall optimal arrangement and planning. This requires the coordination and cooperation between the parties in the supply chain through information systems and integrated management. The high integration and high information sharing of the supply chain system requires big data technology to achieve rapid data capture, discovery, analysis and give correct and timely response, ultimately improving the customer service experience and enhancing the ability of the entire supply chain system to respond to the market environment [1].

Big data technology is the collection, mining, analysis and utilization of information, which has great meaning to the operation and optimization of the supply chain. 


\section{The Defects of the Traditional Clothing Retail Supply Chain Operation}

The supply chain members of the clothing retail industry include fabric accessories suppliers, fashion designers, garment manufacturers and distributors, retailers, etc. The supply chain operation process is the fashion designer to capture market demand, fashion elements, to finish the design of the products. After that a new product launch conference was held. Each distributor placed an order at the product launch conference. The garment manufacturer purchased the fabric accessories according to the order and then finish the produce process. The garments were produced and stored in their own warehouses, and then shipped to the distributors and direct sale stores, according to the order, and finally completed the sale.

Due to the characteristics of clothing retail industry, such as short sales cycle, small purchase volume, strong seasonality, high return ratio, and large difference in demand in different time zones in different regions, the clothing products have high requirements for logistics effectiveness and difficult inventory management. The supply chain management is difficult. The main defects of the traditional clothing retail supply chain operation are:

The Product Information Traceability System Is Not Perfect. Information on the origin of clothing, the origin of surface materials, printing and dyeing processing, etc. are incomplete and cannot provide consumers with visual information.

Supply and Demand Do Not Match. In the traditional clothing retail industry, often because the information is not smooth, it is difficult for upstream enterprises to accurately grasp the downstream market demand information, which will lead to the supply chain manufacturers' design and manufacturing links cannot accurately grasp the market demand, resulting in a mismatch between supply and demand in the supply chain. On the one hand, the customer can't find the right product, the demand is not satisfied, on the other hand, the enterprise has the phenomenon that the product cannot be sold.

The Supply Chain Cannot Respond Quickly to Market Changes. Enterprises in the entire supply chain cannot accurately grasp the downstream market demand information, and cannot achieve efficient coordination. Therefore, they cannot respond quickly to market demands, and often have long production cycles and measures for market opportunities.

The Inventory Backlog or Shortage is Serious. The complexity of the circulation of the clothing retail industry makes the storage of goods large. Under the supply chain bullwhip effect, the demand information is often distorted, resulting in inventory backlog and engulfing the supply chain profit.

The emergence of big data provides a good way to solve these problems for enterprises. Use big data technology to carry out in-depth information mining and analysis on product chain design, manufacturing, procurement, logistics and other aspects of the supply chain, and accurately control each link, adjust demand through big data analysis, optimize supply network, and finally Greatly improve the competitiveness of the entire supply chain[2].

\section{The Supply Chain Optimization Strategy of Clothing Retail Industry under the Background of Big Data}

Establish a Product Information Traceability System based on Big Data, Anti-fake and Anti-channel conflict. Through the storage and collection of data in each link of the apparel supply chain, and using the information platform for data sharing, full traces, real-time traceability, online and offline integration, etc., the entire process traceability of apparel products can be realized, through the product traceability system. Consumers can scan the QR code to detect the authenticity, raw material origin, printing and dyeing, logistics and other processes, which can greatly increase the added value of goods.

For example, using information platforms to provide consumers with visual information, consumers can see the entire process of clothing from raw materials, surface materials to printing and dyeing. This is especially important for maternal and child garments with high environmental performance requirements or high-end branded apparel. It can improve product image, improve 
product quality, improve consumer purchase information, and promote sales.

Use Big Data to Analyze Product Demand Information to Achieve Precise Marketing. Retailers in a big data environment can use rich customer purchase data to analyze consumer personalized user behavior, including purchase time, location, order category, quantity, consumption feedback, evaluation, etc., on consumer groups, behaviors, preferences, System differentiation and in-depth mining of requirements, levels, levels, etc., to achieve accurate marketing. At the same time, based on the establishment of forecasts of consumer spending behavior, effectively guide consumption.

Apparel retailers also monitor customers' in-store movements and interactions with merchandise. They combine this data with transaction records to analyze, which gives advice on which products to sell, how to place the goods, and when to adjust the price. This approach has helped a leading retailer reduce inventory by $17 \%$. At the same time, under the premise of maintaining market share, the proportion of high-margin self-owned brands has increased[3].

According to the analysis and mining of the network text, the customer's feedback on the product is analyzed. For example, the consumer's evaluation of the clothing product's evaluation, preferences, suggestions and other information on the e-commerce platform can form rich big data and customer group portraits. Help production and design companies to carry out targeted innovations and develop better products that are more in line with consumer needs.

Targeted precision marketing can also be achieved using data on social platforms. For example, Informatica's technology helps a retailer enrich customer master data with data on social platforms, making his business services more targeted. By collecting social information from Twitter and Facebook, they gained a deeper understanding of the marketing model of cosmetics, and then they realized that they must retain two types of valuable customers: high consumers and high influencers. I hope that by accepting free makeup services, users can promote word of mouth. This is the perfect combination of transaction data and interactive data, providing solutions for business challenges[3].

Utilize Big Data Analysis to Improve Supply Chain Response Speed and Collaboration. In the era of big data, information sharing between enterprises in the supply chain is more transparent and smooth, which can effectively alleviate information asymmetry in the supply chain. Through the data platform, suppliers, designers, manufacturers, retailers, etc. in the supply chain share sales information and customer feedback, which can greatly improve the response speed and collaboration capabilities of the supply chain.

The cooperation of brand companies and retailers can not only gain insight into market trends, intelligent selections, dynamic pricing, sales analysis and optimization, but also a series of intelligent capabilities through data acquisition. They can also accurately understand consumer needs and do personalized business.

In the process of clothing sales and after-sales, share consumer purchase information, online search information, offline experience information, and after-sales information evaluation, etc., timely grasp the consumer demand dynamics, through the analysis of big data results, manufacturers can flexibly adjust the design Plans and production plans to seize market opportunities.

Based on data analysis, forecast demand can also be used as a reference for dealers and retailers' commodity storage. For example, in the quarterly trade fair, Adidas will use data analysis to help dealers choose the most suitable products, dealers no longer need to make orders according to their personal preferences and heads.

With big data, you can achieve synergy between e-commerce platforms and suppliers. For example, the Y division of JD.com focuses on the integrated analysis of the massive data deposited by the consumer and provides a series of user analysis services to support its users' research, selection, sales policies, smart replenishment, etc. A series of activities called a bridge connecting consumers and producers.

Jingdong Platform will identify the driving force behind category growth through the trend growth positioning model, and then guide and help upstream partners (such as brands, suppliers, manufacturers) to dig deeper into the market segments. In addition to the existing market, the 
platform can also find the "blue ocean of the market" through the "potential market analysis model'[4].

\section{Establish a Retail-Based Warehouse Storage System Based on Big Data , Reduce Inventory} and Out of Stock. The volatility of demand has a huge impact on costs. The greater the volatility, the more safety stocks are needed. The use of big data to achieve better demand forecasting can reduce safety stocks.

Based on the prediction of demand for big data, the establishment of a tiered warehouse inventory plan can effectively reduce inventory and reduce shortages.

In the tiered warehouse inventory plan, the high frequency and low frequency commodities are first classified and stored. High-frequency goods can be efficiently distributed at close range by taking advantage of the local warehouse. The intermediate frequency goods can be placed in the transfer warehouse, and then transferred to the local distribution. Low-frequency goods are delivered remotely in the regional center warehouse. The goods of different frequencies are effectively distributed separately, so as not to drag the system during the storage process. This kind of matching method can effectively shorten the transportation mileage. The hot-selling products are delivered by the city's three-level warehouse (HUB), and the general-purpose goods and long-tail goods are distributed by the first-level warehouse and the second-level warehouse (RDC/CDC). Improve logistics indicators such as vehicle arrival rate, FCL arrival rate, and overall arrival rate.

If the demand for large quantities of liquid goods is more consistent with the forecast, they will be stored in the store. Products that are small and have low liquidity need to be stored in a centralized manner to cope with the demand for online shopping. Those with less demand and high uncertainty need higher safety stocks. Centralizing these inventories can reduce safety by reducing the uncertainty in the demand within the combined area. That is to say, for a large amount of goods with fast flow, a push strategy is adopted, while for a small quantity and a slow flow of goods, a push-pull strategy is adopted[5].

Based on Big Data to Establish End Distribution System to Enhance Customer Experience.

With big data analysis, the required goods can be laid out in advance to the warehouse closest to the consumer, realizing immediate logistics needs and greatly improving the customer experience.

The physical retail chain enterprise can use the storefront to deliver goods, use the store as the showroom of the company's clothing products and the front warehouse, that is, the consumer supply localization, and the city distribution line further forms a supply and demand system within a distance of 60 minutes. Optimize the end warehouse and distribution to achieve seamless docking of the "New Retail", the city line will further solidify the supply and demand relationship within 3 $\mathrm{km}$, many goods do not need to be shipped from the centralized warehouse. Future near distance distribution will become the most important fulcrum of logistics. The warehouse can be seamlessly docked from the nearest warehouse or even the physical store, so that the goods can reach the customer at the lowest cost and fastest speed.

At the same time, the use of big data analysis can also optimize the location of the store. By analyzing transaction data, who buys, the amount of consumption, the frequency of consumption, etc., can accurately guide the retailers to open new stores in which areas, improve the accuracy of the store, here also reflects the advantages of applying big data.

\section{Conclusion}

In the information age, big data has become an emerging strategic asset and core competitiveness of enterprises. The effective use of big data has become one of the key factors determining the success or failure of modern enterprises. There are many defects in the supply chain of traditional clothing enterprises, which leads to the situation that the finished clothes cannot meet the market demand in time, the consumers cannot find the favorite clothing, the inventory of the clothing enterprises is large, and often the discount processing is required. Through the application of big data, we can greatly optimize the supply chain of the apparel industry, realize product traceability, customer classification, precise marketing, improve supply chain response speed and collaboration capability, 
realize intelligent forecasting of warehouse storage, reduce inventory, and improve end-use distribution efficiency. Customer experience and so on, greatly improving the flexibility and overall competitiveness of the apparel retail supply chain.

\section{References}

[1] Supply Chain Management Analysis of Circulation Industry Based on Big Data Perspective, Business Economics Research, 2011.7, pp. 23-25

[2] Wang Hongchun, Liu Shuai, Summary of the application of big data in supply chain management, Logistics Technology, 2017.8, pp. 104-107

[3] Information on http://wiki.mbalib.com/wiki/Big Data

[4] Yang Qingqing, Giants fought in the retail industry big data, Jingdong takes out wisdom supply chain, 21st Century Business Herald, 2018,6,21

[5] Beauty David Hinch-Levy, Philip Kaminsky Edith Hinch-Levy, Supply Chain Design and Management, pp.123 